\title{
Óleos essenciais e extratos vegetais no controle da podridão mole em alface crespa
}

\author{
Cristiane L Silva $^{1}$; Elineide B Souza ${ }^{1}$; Kátia CS Felix ${ }^{1}$; Alice MG Santos ${ }^{1}$; Márcia V Silva² ${ }^{2}$ Rosa LR Mariano ${ }^{1}$ \\ ${ }^{1}$ UFRPE, Programa de Pós-graduação em Fitopatologia, Av. Dom Manoel de Medeiros s/n, Dois Irmãos, 52171-900 Recife-PE; clsagro@ \\ hotmail.com; rrmbac@gmail.com; ㄹFPE-Depto. Bioquímica e Biofísica, Av. Prof. Moraes Rego 1235, Cidade Universitária, 50670-901 \\ Recife-PE
}

\section{RESUMO}

Avaliou-se o efeito de óleos essenciais e extratos vegetais no controle da podridão mole em alface, bem como, a influência desses produtos nas características físico-químicas desta hortaliça. Nos testes in vitro, discos de papel de filtro foram embebidos em 11 óleos essenciais e 20 extratos vegetais nas concentrações 0,$0 ; 0,25 ; 0,50$; 0,75 e $1 \%$ e 0,$0 ; 10,40,70$ e $100 \%$, respectivamente, e depositados sobre meio de cultura contendo Pectobacterium carotovorum subsp. carotovorum (Pcc A1). Os halos de inibição foram mensurados após 24 e 48 h de incubação. Em casa de vegetação, plantas de alface cv. Veneranda foram tratadas com 11 óleos nas concentrações de 0,5 e $1 \%$, 20 extratos na concentração de $10 \%$ e $\operatorname{Mycoshield}{ }^{\circledR}\left(3 \mathrm{~g} \mathrm{~L}^{-1}\right)$, sendo inoculadas com o isolado Pcc A1 após $72 \mathrm{~h}$. A severidade da doença foi avaliada a intervalos de seis até $48 \mathrm{~h}$, calculando-se a área abaixo da curva de progresso da doença (AACPD). Em experimento similar, plantas tratadas com óleo de Corymbia citriodora, sete extratos e Mycoshield ${ }^{\circledR}$ foram analisadas quanto aos teores de sólidos solúveis, vitamina $\mathrm{C}$, acidez titulável e $\mathrm{pH}$. Pcc A1 não foi inibido in vitro. Dois óleos (C. citriodora e Citrus sinensis) e sete extratos (Parkinsonia aculeata, Chamaecrista cytisoides, Sida galherensis, Polygala violaceae, Chamaecrista desvauxii e Pityrocarpa moniliformis) reduziram significativamente a severidade da doença em relação à testemunha, não diferindo do controle Mycoshield ${ }^{\circledR}$. Já a AACPD foi reduzida por oito óleos e dez extratos. Destacaram-se com eficiência similar ao Mycoshield ${ }^{\circledR}$ e diferindo da testemunha $(7,5$ e 132,3 ) nas duas variáveis analisadas, o óleo de C. citriodora a $0,5 \%$ e o extrato de $S$. galherensis a $10 \%$ com severidades de 3,6 e 3,5 e AACPD de 83,35 e 88,25, respectivamente. Os teores de vitamina C, acidez titulável e $\mathrm{pH}$ não foram alterados em folhas de alface tratadas com óleo de C. citriodora e extratos de P. aculeata e C. cytisoides.

Palavras-chave: Lactuca sativa, Pectobacterium carotovorum subsp. carotovorum, controle alternativo.

\section{ABSTRACT \\ Essential oils and plant extracts on the control of soft rot of crispy lettuce}

The effect of oils and plant extracts was evaluated for controlling soft rot in lettuce and assessed the influence of these products in physico-chemical characteristics of this vegetable. In the in vitro tests, filter paper discs were soaked in eleven essential oils $(0.0,0.25$, $0.50,0.75$ and $1 \%)$ and twenty plant extracts $(10,40,70$ and $100 \%)$ being deposited on a culture medium containing Pectobacterium carotovorum subsp. carotovorum (strain Pcc A1). The zones of inhibition were measured after 24 and $48 \mathrm{~h}$ of incubation. In the greenhouse, plants of cv. Veneranda were treated with eleven oils $(0.5$ and $1 \%)$, twenty extracts $(10 \%)$ and Mycoshield ${ }^{\circledR}\left(3 \mathrm{~g} \mathrm{~L}^{-1}\right)$ and after $72 \mathrm{~h}$ were inoculated with Pcc A1. We evaluated the disease severity with an interval of six hours until $48 \mathrm{~h}$, and the area under the disease progress curve (AUDPC) was calculated. In a similar experiment plants treated with Corymbia citriodora oil, seven plant extracts and Mycoshield ${ }^{\circledR}$ were analyzed for soluble solids, vitamin C, acidity and $\mathrm{pH}$. Strain Pcc A1 was not inhibited in vitro. Two oils $(C$. citriodora and C. sinensis) and seven extracts (Parkinsonia aculeata, Chamaecrista cytisoides, Sida galherensis, Polygala violaceae, C. desvauxii and Pityrocarpa moniliformis) significantly reduced disease severity in comparison to control, without differing from Mycoshield $^{\circledR}$. On the other hand AACPD was reduced by eight oils and ten extracts. It is worth to notice that severity and AUDPC were reduced by eucalyptus oil at $0.5 \%(3.6,83.35)$ and by the extract of S. galherensis $(3.5,88.25)$ with the same efficiency as Mycoshield ${ }^{\circledR}$ when compared to control $(7.5,132.3)$. The levels of vitamin $C$, acidity and $\mathrm{pH}$ were not altered in leaves of lettuce treated with eucalyptus oil and extracts of P. aculeata and C. cytisoides.

Keywords: Lactuca sativa, Pectobacterium carotovorum subsp. carotovorum, alternative control.

\section{(Recebido para publicação em 26 de abril de 2011; aceito em 3 de agosto de 2012) (Received on April 26, 2011; accepted on August 3, 2012)}

\begin{abstract}
A alface (Lactuca sativa) é uma hortaliça muito cultivada especialmente por suas folhas que são consumidas cruas em saladas. No Brasil, destaca-se por seu grande valor comercial, sendo a sexta hortaliça em importância econômica e oitava em termos de produção (Oliveira et al., 2005). Alguns fatores têm limitado o rendimento, a lucratividade e o sucesso
\end{abstract}

da produção de alface, estando as doenças entre os mais importantes, com destaque para a podridão mole causada por Pectobacterium carotovorum subsp. carotovorum. No ano de 2004, levantamento sobre esta doença nas mesorregiões da Mata e Agreste pernambucano, constatou em todas as áreas produtoras amostradas uma prevalência de 42,9\%.
A incidência da doença em alface variou de 0 a 22\% (Silva et al., 2007). A podridão mole causa grandes perdas uma vez que $P$. carotovorum subsp. carotovorum tem elevada capacidade de sobrevivência, ampla gama de hospedeiros, alta variabilidade e não existem agroquímicos eficientes para seu controle.

O controle de doenças, pragas e

Parte da dissertação de Mestrado do primeiro autor apresentada ao Programa de Pós-Graduação em Fitopatologia (UFRPE) 
plantas invasoras ainda representa um grande desafio na busca por uma agricultura sustentável. A conscientização acerca dos problemas ambientais causados pelo uso dos agroquímicos, e consequente busca pela redução do seu uso, permite o avanço das pesquisas na obtenção de tecnologias e produtos, vários deles já utilizados no passado de forma empírica, para o manejo fitossanitário (Silva et al., 2010). Nesse contexto, o uso de óleos e extratos vegetais ou de metabólitos secundários de plantas é uma ferramenta a mais a ser incorporada nos sistemas alternativos de produção de alimentos e nos sistemas convencionais como forma de aumentar a sustentabilidade e segurança dos mesmos (Silva et al., 2010).

Vários autores estudaram os efeitos de óleos essenciais sobre o agente causal da podridão mole. Costa et al. (2008) constataram que o óleo puro de citronela (Cymbopogon winterianus) foi mais efetivo do que o antibiótico tetraciclina na inibição do crescimento de seis isolados de $P$. carotovorum subsp. carotovorum. Também Jeong et al. (2009) observaram atividade inibitória do óleo essencial de capimlimão (Cymbopogon citratus) sobre três isolados de $P$. carotovorum subsp. carotovorum, com completa inibição do crescimento após $48 \mathrm{~h}$ de incubação.

Nenhum trabalho foi encontrado na literatura consultada utilizando óleos ou extratos vegetais para controle da podridão mole em alface, embora haja um relato do controle desta doença em cebola (Allium cepa). Neste caso, observou-se redução no desenvolvimento da podridão mole (56\%) em bulbos polvilhados com sementes moídas de nabo (Brassica napus) cv. Kana e inoculados com $P$. carotovorum subsp. carotovorum, assim como $28 \%$ de redução na doença em bulbos tratados com extrato aquoso de tomateiro (Solanum lycopersicon) cv. Remiz (Kwalska \& Smolinska, 2008).

No caso da utilização de produtos alternativos para o controle de doenças em hortaliças comestíveis in natura, como as folhosas e principalmente, a alface, é necessário determinar se os tratamentos utilizados não irão alterar a qualidade do produto vegetal. Dentre os índices de qualidade mais importantes encontram-se as características físicoquímicas: sólidos solúveis, vitamina $\mathrm{C}$, acidez titulável e $\mathrm{pH}$. Não foram encontrados padrões de teores desejáveis para estas variáveis. Entretanto, Yaguiu (2008) obteve para alface cv. Lisa cultivada em sistema convencional, valores médios de sólidos solúveis, vitamina $\mathrm{C}$, acidez titulável e $\mathrm{pH}$ de 2,81 ; 23,02; 0,06 e 7,0, respectivamente.

Devido à importância da podridão mole como fator limitante para a produção de alface em algumas áreas do estado de Pernambuco e a dificuldade de medidas efetivas de controle para esta doença, o objetivo deste trabalho foi avaliar o efeito de óleos essenciais e extratos vegetais no controle da podridão mole, bem como, avaliar a influência desses produtos em características físico-químicas desta hortaliça.

\section{MATERIAL E MÉTODOS}

Obtenção do isolado de Pectobacterium carotovorum subsp. carotovorum - $\mathrm{O}$ isolado de $P$. carotovorum subsp. carotovorum (Pcc A1) foi obtido de planta de alface com sintomas de podridão mole em plantio no município de Chã GrandePE e preservado em água esterilizada (Mariano \& Silveira, 2005). Para utilização nos experimentos, o isolado foi cultivado em meio CPG (caseína hidrolisada $1 \mathrm{~g}$, peptona $10 \mathrm{~g}$, dextrose $10 \mathrm{~g}$, ágar $18 \mathrm{~g}$, água destilada $1 \mathrm{~L})$ pelo método de estrias (Mariano \& Silveira, 2005) por $48 \mathrm{~h}$ à temperatura de $28^{\circ} \mathrm{C}$. Após este período, água destilada esterilizada foi adicionada à placa de Petri contendo o crescimento bacteriano e a concentração da suspensão foi ajustada em fotocolorímetro (Analyser ${ }^{\circledR}$ ) a $570 \mathrm{~nm}$ de absorbância $\left(\mathrm{A}_{570 \mathrm{~nm}}\right)$, de acordo com equação pré-estabelecida, onde $\mathrm{A}_{570}=0,36$ equivale a $1,0 \times 10^{9}$ UFC mL-1.

Plantio - Os experimentos foram realizados com a alface crespa $\mathrm{cv}$. Veneranda usualmente cultivada nas áreas produtoras da Mesorregião da Mata Pernambucana. Mudas desta cultivar, com 20 dias de idade, foram adquiridas em Natuba, área rural de Vitória de
Santo Antão-PE. O transplantio foi realizado imediatamente para vasos com capacidade de 1 L contendo a mistura de solo esterilizado e húmus, na proporção $1: 1$ (v:v) e as plântulas foram mantidas em casa de vegetação, onde a temperatura variou de 25 a $30^{\circ} \mathrm{C}$, sendo irrigadas conforme necessário.

\section{Obtenção dos óleos essenciais e extratos vegetais \\ óleos essenciais - Os óleos} essenciais de canela (Cinnamomum zeylanicum), bergamota (Citrus aurantium var. bergamia), manjericão (Ocimum basilicum), gengibre (Zingiber officinale), eucalipto citriodora (Corymbia citriodora), eucalipto globulus (Eucalyptus globulus), capimlimão (C. citratus), limão (Citrus limon), laranja-doce (Citrus sinensis), erva-doce (Foeniculum vulgare), sálviaesclaréia (Salvia sclarea) da marca Bioessência (Jaú-SP) foram adquiridos em estabelecimento comercial. Estes óleos foram armazenados em laboratório em frascos de vidro cor âmbar com tampa de rosca a temperatura de $25 \pm 2^{\circ} \mathrm{C}$.

Extratos vegetais - As coletas das espécies vegetais foram realizadas de junho/2009 a setembro/2010, no Parque Nacional do Catimbau (Buíque, Tupanatinga e Ibimirim, PE) e Estação Experimental do IPA (Serra TalhadaPE). As espécies coletadas foram: folhas e ramos de angico (Anadenanthera colubrina var. cebil); ramos de imburana (Cammiphora leptophloeos); folhas de vassourinha (Chamaecrista cytisoides); ramos, frutos e folhas de vassourinha (Chamaecrista desvauxii); folhas de Chamaecrista sp.; folhas de cutia (Eugenia brejoensis); folhas de jatobá (Hymenaea courbaril var. courbaril); folhas de pau ferro (Libidibia ferrea); casca de aroeira do sertão (Myracrodruoun urundeuva); ramos de bálsamo (Myroxylon peruiferum); folhas e ramos com espinhos de turco (Parkinsonia aculeata); folhas e ramos de angico de bezerro (Pityrocarpa moniliformis); ramos de Polygala violacea e ramos e raízes de malva branca (Sida galheirensis). Os órgãos vegetais foram desidratados em estufa a $40^{\circ} \mathrm{C}$ durante $48 \mathrm{~h}$, quando se realizou a trituração do material que foi armazenado em frascos de vidro 
cor âmbar com tampa de rosca até o preparo do extrato hidro-alcoólico. Para isto, $1 \mathrm{~g}$ de cada material foi adicionado a $9 \mathrm{~mL}$ de álcool etílico a $70 \%$ por 24 h no escuro, seguindo-se filtração em gaze esterilizada, sendo o filtrado colocado em estufa a $50^{\circ} \mathrm{C}$ por $72 \mathrm{~h}$ para a completa evaporação do solvente. A partir do peso do extrato bruto resultante, denominado rendimento, foi calculada a quantidade de água a ser adicionada para ressuspensão e obtenção do extrato a 100\% (Cunico et al., 2003; Leite et al., 2006; Michelin et al., 2008). Estes extratos foram armazenados em frascos de vidro cor âmbar com tampa de rosca, à temperatura de $25 \pm 2^{\circ} \mathrm{C}$ por três meses.

Efeito dos óleos essenciais e extratos vegetais sobre o crescimento de Pectobacterium carotovorum subsp. carotovorum - Para realizar o teste do antibiograma a suspensão bacteriana foi preparada conforme já descrito e uma alíquota de $2 \mathrm{~mL}$ foi adicionada a cada $100 \mathrm{~mL}$ de meio CPG fundente, homogeneizado e distribuído em placas de Petri. Cinco discos esterilizados de papel filtro Whatman $n^{\circ} 1$, contendo os 11 óleos essenciais nas concentrações 0,0 (testemunha com água esterilizada), 0,$25 ; 0,5 ; 0,75$ e $1 \%$ foram distribuídos equidistantes em cada placa. A incubação foi feita a $29^{\circ} \mathrm{C}$ e a avaliação realizada após 24 e $48 \mathrm{~h}$ medindo-se os halos de inibição com o paquímetro. O delineamento experimental foi inteiramente casualizado em arranjo fatorial 11 x 5 representado por óleos e concentrações, com quatro repetições constituídas por um disco por placa. Este mesmo procedimento foi realizado para testar os 20 extratos nas concentrações 0,$0 ; 10,40,70$ e $100 \%$. Neste caso, o delineamento experimental foi inteiramente casualizado em arranjo fatorial $20 \times 5$ representado pelos extratos e concentrações, com quatro repetições.

Efeito de óleos essenciais e extratos vegetais na redução da severidade da podridão mole em plantas de alface - Os 11 óleos essenciais foram diluídos em água contendo Tween 80 a $1 \%$ e agitados durante 10 minutos antes da pulverização de plantas de alface cv. Veneranda com 40 dias de idade, cultivadas em casa de vegetação.
Para escolha das concentrações a serem utilizadas, todos os óleos foram previamente testados nas plantas de alface. Por causarem fitotoxidez, os óleos de C. zeylanicum, O. basilicum, $F$. vulgare, C. citriodora, S. sclarea, $Z$. officinale e $C$. citratus foram utilizados na concentração $0,5 \%$ e os óleos de $C$. aurantium var. bergamia, $C$. limon, $C$. sinensis e E. globulus na concentração $1,0 \%$. Os 20 extratos também foram testados na concentração de 10\%. Após 72 h das aplicações, dos óleos e extratos, as plantas foram inoculadas com Pcc A1 na base do pecíolo da segunda e terceira folhas definitivas pelo método de picada. Este método consiste no ferimento do tecido vegetal com alfinete na profundidade de $1 \mathrm{~mm}$, seguindo-se a deposição de $10 \mu \mathrm{L}$ de suspensão bacteriana, com concentração de $1,0 \times 10^{9}$ UFC $\mathrm{mL}^{-1}$, com auxílio de um micropipetador (Mariano \& Silveira, 2005). Após a inoculação, as plantas foram submetidas à câmara úmida, constituída por sacos plásticos umedecidos, durante seis horas em casa de vegetação. O delineamento experimental foi inteiramente casualizado com 33 tratamentos (11 óleos essenciais e 20 extratos vegetais) incluindo a testemunha relativa (pulverizada com água) e a testemunha pulverizada com o antibiótico agrícola Mycoshield ${ }^{\circledR}$ na concentração de 3 $\mathrm{g} \mathrm{L}^{-1}$ de água. Cada tratamento teve cinco repetições, constituídas por uma planta. As avaliações foram realizadas a intervalos de seis horas até 48 horas, observando-se a severidade da doença, estimada com o auxílio de escala descritiva de 1 a 9 (Ren et al., 2001), onde: $1=$ sem lesão no ponto de inoculação, $2=$ lesões menores que $5 \mathrm{~mm}, 3=$ lesões entre 5 e $10 \mathrm{~mm}, 4=$ lesões maiores que $10 \mathrm{~mm}$, porém não atingindo as folhas, $5=$ lesão alcançando o limbo foliar e o caule principal, $6=$ caule infectado, porém sem atingir as folhas não inoculadas, $7=$ caule e folhas não inoculadas infectadas, $8=$ planta inteira próxima à morte e $9=$ planta morta. Com os dados da severidade foi calculada a área abaixo da curva de progresso da doença $(\mathrm{AACPD})$ pela expressão: $\mathrm{AACPD}=\mathrm{S}$ $\left(\mathrm{y}_{\mathrm{i}}+\mathrm{y}_{\mathrm{i}+1}\right) / 2 . \mathrm{d}_{\mathrm{ti}}$, onde $\mathrm{y}_{\mathrm{i}}$ e $\mathrm{y}_{\mathrm{i}+1}$ são os valores de severidade observados em duas avaliações consecutivas, $\mathrm{d}_{\mathrm{ti}} \mathrm{o}$ intervalo entre as avaliações e n é a duração do período de avaliação (Shaner \& Finney, 1977).

Análise físico-química de folhas de alface tratadas com óleo essencial e extratos vegetais - Este experimento foi realizado para analisar características físico-químicas de plantas tratadas com óleo essencial e extratos após a inoculação com Pcc A1. A metodologia foi a mesma utilizada no experimento para análise da redução da severidade da podridão mole em plantas de alface. Foram selecionados nove tratamentos constituídos pelos extratos de $C$. desvauxii (folhas), $P$. aculeata (folhas e ramos com espinhos), $P$. violacea (ramos), S. galheirensis (raiz), $C$. cytisoides (folhas) (10\%), óleo essencial de $C$. citriodora $(0,5 \%)$, antibiótico agrícola Mycoshield ${ }^{\circledR}\left(3 \mathrm{~g} \mathrm{~L}^{-1}\right)$ e a testemunha relativa. Três dias após a aplicação dos produtos, as plantas de alface foram inoculadas com Pcc A1 e após 48 h coletadas e levadas ao Laboratório de Patologia Pós-colheita da UFRPE para serem avaliados os teores de sólidos solúveis (SS), ácido ascórbico (vitamina $\mathrm{C}$ ), acidez titulável (AT) e potencial hidrogeniônico $(\mathrm{pH})$. As características foram determinadas após a trituração das folhas de alface em centrífuga doméstica. Na determinação da vitamina $\mathrm{C}$ utilizou-se o método de Tillman modificado (Bezerra Neto et al., 2004; Zenebon et al., 2008). Os conteúdos de SS e a AT foram determinados seguindo a metodologia descrita por Freire et al. (2009). O pH foi determinado no material homogeneizado utilizando-se um potenciômetro digital modelo Corning $445^{\circledR}$ calibrado com soluções tampão de pH 4,0 e 7,0. $\mathrm{O}$ experimento teve delineamento inteiramente casualizado, com nove tratamentos e quatro repetições, constituídas por uma planta.

Análises estatísticas - Todos os experimentos foram repetidos. As análises estatísticas foram realizadas com o auxílio dos programas STATISTIX $^{\circledR}$ (versão 9.0, Analytical Software, Tallahassee) e SAEG ${ }^{\circledR}$ (versão 9.0, Sistema de Análises Estatísticas e Genéticas, UFV, 2005). 
Tabela 1. Efeito de óleos essenciais, extratos vegetais e do antibiótico agrícola Mycoshield ${ }^{\circledR}$, em diferentes concentrações, no controle da podridão mole em plantas de alface na casa de vegetação, avaliado pela severidade e área abaixo da curva de progresso da doença após $48 \mathrm{~h}$ de avaliação (effect of essential oils, plant extracts and antibiotic Mycoshield ${ }^{\circledR}$ at different concentrations in the control of soft rot of lettuce in the greenhouse, as assessed by disease severity and area under the disease progress curve after $48 \mathrm{~h}$ observation). Recife, UFRPE, 2010.

\begin{tabular}{|c|c|c|c|c|}
\hline Tratamentos & $\begin{array}{c}\text { Concentrações } \\
(\%)\end{array}$ & $\begin{array}{c}\text { Forma do } \\
\text { produto }^{1}\end{array}$ & Severidade & $\mathbf{A A C P D}^{2}$ \\
\hline Testemunha $^{3}$ & - & A & $7,5^{4} \mathrm{a}$ & $132,30^{5} \mathrm{a}$ \\
\hline Cammiphora leptophloeos (ramos) & 10 & $\mathrm{E}$ & $6,0 \mathrm{ab}$ & $127,00 \mathrm{a}$ \\
\hline Ocimum basilicum & 0,5 & $\mathrm{O}$ & $5,5 \mathrm{abc}$ & $123,35 \mathrm{a}$ \\
\hline Anadenanthera colubrina var. colubrina (folhas) & 10 & $\mathrm{E}$ & $5,3 \mathrm{abc}$ & $125,45 \mathrm{a}$ \\
\hline Libidibia ferrea var. ferrea (folhas) & 10 & $\mathrm{E}$ & $5,1 \mathrm{abc}$ & $125,45 \mathrm{a}$ \\
\hline Citrus limon & 1 & $\mathrm{O}$ & 4,6 abc & $104,40 \mathrm{~b}$ \\
\hline Citrus aurantium var. bergamia & 1 & $\mathrm{O}$ & $4,6 \mathrm{abc}$ & $117,30 \mathrm{a}$ \\
\hline Eugenia brejoensis (folhas) & 10 & $\mathrm{E}$ & $4,7 \mathrm{abc}$ & $115,50 \mathrm{a}$ \\
\hline Chamaecrista desvauxii (ramos) & 10 & $\mathrm{E}$ & $4,5 \mathrm{abc}$ & $117,30 \mathrm{a}$ \\
\hline Salvia sclarea & 0,5 & $\mathrm{O}$ & $4,7 \mathrm{abc}$ & $106,20 \mathrm{~b}$ \\
\hline Chamaecrista desvauxii (fruto) & 10 & $\mathrm{E}$ & $4,4 \mathrm{abc}$ & $123,80 \mathrm{a}$ \\
\hline Eucalyptus globulus & 1 & $\mathrm{O}$ & $4,4 \mathrm{abc}$ & $100,55 \mathrm{~b}$ \\
\hline Hymenaea courbaril var. courbaril (folhas) & 10 & $\mathrm{E}$ & $4,4 \mathrm{abc}$ & $103,30 \mathrm{~b}$ \\
\hline Myroxylon peruiferum (ramos) & 10 & $\mathrm{E}$ & $4,5 \mathrm{abc}$ & $117,90 \mathrm{a}$ \\
\hline Cinnamomum zeylanicum & 0,5 & $\mathrm{O}$ & $4,3 \mathrm{abc}$ & $110,60 \mathrm{a}$ \\
\hline Zingiber officinale & 0,5 & $\mathrm{O}$ & $4,3 \mathrm{abc}$ & $106,85 \mathrm{~b}$ \\
\hline Foeniculum vulgare & 0,5 & $\mathrm{O}$ & $4,3 \mathrm{abc}$ & $105,20 \mathrm{~b}$ \\
\hline Chamaecrista sp. (folhas) & 10 & $\mathrm{E}$ & $4,4 \mathrm{abc}$ & $106,30 \mathrm{~b}$ \\
\hline Pityrocarpa moniliformis (folhas) & 10 & $\mathrm{E}$ & $4,2 \mathrm{abc}$ & $113,05 \mathrm{a}$ \\
\hline Sida galheirensis (ramos) & 10 & $\mathrm{E}$ & $4,2 \mathrm{abc}$ & $117,30 \mathrm{a}$ \\
\hline Anadenanthera colubrina var. colubrina (ramos) & 10 & $\mathrm{E}$ & 4,2 abc & $115,50 \mathrm{a}$ \\
\hline Cymbopogon citratus & 0,5 & $\mathrm{O}$ & $4,0 \mathrm{abc}$ & $98,40 \mathrm{~b}$ \\
\hline Myracrodruoun urundeuva (casca) & 10 & $\mathrm{E}$ & 4,4 abc & $101,95 \mathrm{~b}$ \\
\hline Pityrocarpa moniliformis (ramos) & 10 & $\mathrm{E}$ & $4,0 \mathrm{bc}$ & $105,40 \mathrm{~b}$ \\
\hline Citrus sinensis & 1 & $\mathrm{O}$ & $4,1 \mathrm{bc}$ & $96,30 \mathrm{~b}$ \\
\hline Parkinsonia aculeata (folhas) & 10 & $\mathrm{E}$ & $3,7 \mathrm{bc}$ & $94,35 \mathrm{~b}$ \\
\hline Chamaecrista desvauxii (folhas) & 10 & $\mathrm{E}$ & $3,7 \mathrm{bc}$ & $102,95 \mathrm{~b}$ \\
\hline Corymbia citriodora & 0,5 & $\mathrm{O}$ & $3,6 \mathrm{bc}$ & $83,35 \mathrm{c}$ \\
\hline Polygala violacea (ramos) & 10 & $\mathrm{E}$ & $3,6 \mathrm{bc}$ & $97,75 \mathrm{~b}$ \\
\hline Sida galherensis (raiz) & 10 & $\mathrm{E}$ & $3,5 \mathrm{bc}$ & $88,25 \mathrm{c}$ \\
\hline Chamaecrista cytisoides (folhas) & 10 & $\mathrm{E}$ & $3,4 \mathrm{bc}$ & $95,45 \mathrm{~b}$ \\
\hline Parkinsonia aculeata (ramos com espinhos) & 10 & $\mathrm{E}$ & $3,3 \mathrm{c}$ & $96,85 \mathrm{~b}$ \\
\hline Mycoshield $^{\circledR} 6$ & $3 \mathrm{~g} \mathrm{~L}^{-1}$ & PM & $3,1 \mathrm{c}$ & $68,10 \mathrm{c}$ \\
\hline $\mathrm{CV}(\%)$ & & & 26,0 & 20,6 \\
\hline
\end{tabular}

${ }^{1} \mathrm{~A}=$ água (water) $\mathrm{O}=$ óleo essencial (essencial oil) $\mathrm{E}=$ extrato hidro-alcoólico (hydra-alcoholic extract) $\mathrm{PM}=$ pó molhável (wettable powder);

${ }^{2} \mathrm{AACPD}=$ área abaixo da curva de progresso da doença (area under disease progress curve); ${ }^{3}$ Testemunha = plantas tratadas com água (control $=$ plants treated with water); ${ }^{4}$ Médias seguidas pela mesma letra não diferem entre si pelo teste de Kruskal-Wallis a 5\% de probabilidade; números são médias de dois experimentos (means followed by the same letter do not differ by Kruskal-Wallis test ( $\mathrm{p} \leq 0.05$ ); values are means of two experiments; ${ }^{5}$ Médias seguidas pela mesma letra não diferem entre si pelo teste de Scott-Knott a 5\% de probabilidade; números são médias de dois experimentos (means followed by the same letter do not differ by Scott-Knott test ( $\mathrm{p} \leq 0.05$ ); values are means of two

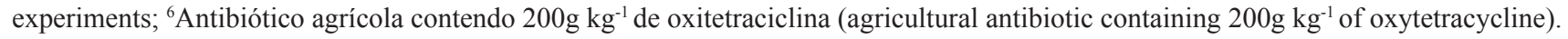

\section{RESULTADOS E DISCUSSÃO}

Obtenção do isolado de Pectobacterium carotovorum subsp. carotovorum - Em todos os experimentos foi utilizado o isolado Pcc A1 de P. carotovorum subsp. carotovorum, que apresentou características típicas da subespécie como, resistência a eritromicina, catalase positiva, comportamento anaeróbico facultativo, capacidade de crescer a $37^{\circ} \mathrm{C}$ e incapacidade de utilizar $\alpha$-metil glucosídios (De Boer \& Kelman, 2001). Pcc A1 é patogênico a plantas de alface 
Tabela 2. Análise físico-química de plantas de alface, pulverizadas com óleo de Corymbia citriodora, extratos vegetais de diversas espécies da caatinga e antibiótico agrícola Mycoshield ${ }^{\mathbb{B}}$, inoculadas por picada com Pectobacterium carotovorum subsp. carotovorum três dias após o tratamento, e coletadas para processamento após 48 h (physico-chemical analysis of lettuce plants sprayed with oil of Corymbia citriodora, plant extracts of several caatinga species and antibiotic Mycoshield ${ }^{\circledR}$, inoculated by pricking with Pectobacterium carotovorum subsp. carotovorum three days after treatment, and collected for processing after 48 h). Recife, UFRPE, 2010.

\begin{tabular}{|c|c|c|c|}
\hline Tratamentos & $\begin{array}{c}\text { VITC }^{1} \\
\text { (mg de ácido ascórbico } 100 \mathrm{~g}^{-1} \text { ) }\end{array}$ & $\begin{array}{c}\text { AT } \\
\text { (\% de ácido cítrico) }\end{array}$ & pH \\
\hline $\operatorname{Mycoshield}^{\circledR}\left(3 \mathrm{~g} \mathrm{~L}^{-1}\right)$ & $28,56^{2} \mathrm{bc}$ & $0,035 \mathrm{~cd}$ & $5,08 \mathrm{a}$ \\
\hline Sida galheirensis (raiz) & $19,04 \mathrm{~d}$ & $0,037 \mathrm{~cd}$ & $4,91 \mathrm{ab}$ \\
\hline Parkinsonia aculeata (ramos com espinhos) & $26,18 \mathrm{bcd}$ & $0,042 \mathrm{~cd}$ & $4,77 \mathrm{abc}$ \\
\hline Chamaecrista cytisoides (folhas) & $21,42 \mathrm{~cd}$ & $0,037 \mathrm{~cd}$ & $4,76 \mathrm{abc}$ \\
\hline Testemunha $^{3}$ & $28,56 \mathrm{bc}$ & $0,032 \mathrm{~d}$ & $4,61 \mathrm{bc}$ \\
\hline Corymbia citriodora & $21,42 \mathrm{~cd}$ & $0,040 \mathrm{~cd}$ & $4,55 \mathrm{bc}$ \\
\hline Polygala violacea (ramos) & $30,94 \mathrm{~b}$ & $0,047 \mathrm{bc}$ & $4,42 \mathrm{~cd}$ \\
\hline Parkinsonia aculeata (folhas) & $26,18 \mathrm{bcd}$ & $0,065 \mathrm{a}$ & $4,07 \mathrm{de}$ \\
\hline Chamaecrista desvauxii (folhas) & $40,46 \mathrm{a}$ & $0,057 \mathrm{ab}$ & $3,82 \mathrm{e}$ \\
\hline $\mathrm{CV}(\%)$ & 14,41 & 12,8 & 3,57 \\
\hline
\end{tabular}

${ }^{1}$ VIT C = Vitamina C (vitamin C); AT= Acidez total titulável (total titratable acidity); ${ }^{2}$ Médias seguidas pela mesma letra não diferem significativamente entre si pelo teste de Tukey $(\mathrm{p} \leq 0,05)$; números são médias de dois experimentos (means followed by the same letter do not differ by Tukey's test ( $\mathrm{p} \leq 0.05)$; values are means of two experiments); ${ }^{3}$ Testemunha $=$ plantas tratadas com água; todas as análises foram realizadas em plantas com 35 dias (control = plants treated with water; all analysis were performed when plants were 35 days old).

e causa maceração do tecido em frutos de pimentão verde.

Efeito de óleos essenciais e extratos vegetais sobre o crescimento de Pectobacterium carotovorum subsp. carotovorum - Nos ensaios in vitro, os 11 óleos essenciais e 20 extratos vegetais, não apresentaram efeito direto sobre o crescimento do isolado Pcc A1. Porém, existem relatos na literatura da eficiência de uma variedade de óleos essenciais e extratos vegetais inibindo in vitro diversos fitopatógenos, inclusive $P$. carotovorum subsp. carotovorum.

Costa et al. (2008) constataram que o óleo puro de $C$. winterianus (citronela) foi mais efetivo do que o antibiótico tetraciclina na inibição do crescimento de seis isolados de $P$. carotovorum subsp. carotovorum, e quando diluído apresentou concentração inibitória mínima de $1 \%$ para todos os isolados. Estes mesmos autores verificaram que só nas maiores concentrações $(2,4$ e $8 \%$ ), o óleo essencial de $O$. basilicum (manjericão) atuou sobre $P$. carotovorum subsp. carotovorum, com formação de halos que variaram entre 10 e $17 \mathrm{~mm}$ (Costa et al., 2009), confirmando os resultados obtidos no presente trabalho em que o óleo de manjericão testado em concentrações abaixo de $1 \%$ não inibiu o crescimento de Pcc A1.

O óleo de C. citratus apresentou atividade inibitória dose-dependente $(0,25 ; 0,5$ e $1,0 \%)$ sobre três isolados de $P$. carotovorum subsp. carotovorum, observando-se a completa inibição do crescimento bacteriano após 48 $\mathrm{h}$ de incubação (Jeong et al., 2009). Estes resultados não corroboram com os obtidos neste trabalho, no qual foram testadas as mesmas dosagens e, no entanto, não foi observado efeito inibitório sobre Pcc A1. Isto pode ser explicado pela diferença na procedência do óleo que inclui condições de cultivo, espécies e partes de plantas, estações do ano, áreas geográficas e métodos de extração, entre outros (Burt, 2004), e ainda pela alta variabilidade do patógeno (Alvarado et al., 2011).

Vigo-Schultz et al. (2006) avaliaram a eficácia da tintura etanólica de Mikania glomerata (guaco) sobre $X$. campestris pv. campestris observando inibição de $38 \%$ na concentração de $1 \mathrm{~g} \mathrm{~L}^{-1} \mathrm{e}$ de $24 \%$ na concentração de $0,5 \mathrm{~g} \mathrm{~L}^{-1}$. Lima et al. (2010) avaliaram o efeito de extratos vegetais de plantas da caatinga, Lippia microphylla (alecrim do campo), Astronium urundeuva (aroeira) e Mimosa hostilis (jurema preta) sobre o crescimento do fungo Lasiodiplodia theobromae, observando-se controle de
100,46 e $30 \%$, respectivamente, após três dias de avaliação. Apesar deste bom resultado obtido na atividade antifúngica de extratos vegetais provenientes de plantas da caatinga, no presente trabalho, os extratos de plantas deste bioma não apresentaram efeito inibitório sobre o crescimento de $P$. carotovorum subsp. carotovorum. Isto pode ser explicado em parte pela especificidade de ação desses metabólitos contra determinados patógenos, entre outros fatores.

Efeito de óleos essenciais e extratos vegetais na redução da severidade da podridão mole em plantas de alface Em casa de vegetação, observou-se que dois óleos (C. citriodora e C. sinensis) e sete extratos ( $P$. aculeata (ramos com espinhos e folhas), $C$. cytisoides (folhas), $S$. galherensis (raiz), $P$. violaceae (ramos), C. desvauxii (folhas) e P. moniliformis (ramos)) reduziram significativamente a severidade da doença em relação à testemunha, não diferindo do controle Mycoshield ${ }^{\circledR}$. Nove óleos e 12 extratos não diferiram da testemunha nem do Mycoshield ${ }^{\circledR}$. Com relação à $\mathrm{AACPD}$, oito óleos essenciais e dez extratos vegetais a reduziram em relação à testemunha, sendo que o óleo de C. citriodora e o extrato de $S$. galherensis (raiz) não 
diferiram do Mycoshield ${ }^{\circledR}$ (Tabela 1).

Destacaram-se com eficiência similar ao Mycoshield ${ }^{\circledR}$ e diferindo da testemunha $(7,5$ e 132,3$)$ nas duas variáveis analisadas, o óleo de $C$. citriodora a $0,5 \%$ e o extrato de $S$. galherensis a $10 \%$ com severidades de 3,6 e 3,5 e AACPD de 83,35 e 88,25, respectivamente (Tabela 1 ).

Mesmo não existindo relatos do efeito de óleos essenciais e extratos vegetais no controle da podridão mole em alface, resultados promissores utilizando esses produtos em outros patossistemas são encontrados. Kowalska \& Smolinska (2008) observaram redução no desenvolvimento da podridão mole (56\%) em bulbos de $A$. cepa (cebola) polvilhados com sementes moídas de $B$. rapa (nabo) cv. Kana e inoculados com P. carotovorum subsp. carotovorum, assim como uma redução de $28 \%$ da doença em bulbos tratados com extrato aquoso de $S$. lycopersicum (tomateiro) cv. Remiz. Redução da severidade da podridão negra causada por $X$. campestris pv. campestris em Brassica oleracea (couve-flor) foi verificada quando tintura etanólica de M. glomerata (guaco) (1 e 0,5 $\left.\mathrm{g} \mathrm{L}^{-1}\right)$ foi aplicada simultaneamente à inoculação do patógeno (Vigo-Schultz et al., 2006). Já o cancro cítrico, causado pela bactéria $X$. axonopodis pv. citri Vauterin teve a severidade reduzida em Citrus limon (limoeiros) pelo extrato aquoso de Tamarindus indica (tamarindo) o qual reduziu em mais de $60 \%$ a infecção de plantas no campo (Leksomboon et al., 2001). Tinturas de Lippia alba (lípia), $M$. glomerata (guaco), Equisetum hyemale (cavalinha) e Hedera helix (hera) foram muito eficientes no controle do crestamento bacteriano comum do Phaseolus vulgaris (feijoeiro) causado por X. axonopodis pv. phaseoli, reduzindo a área abaixo da curva de progresso da doença, com resultados dependentes das dosagens e épocas de aplicação (Vigo et al., 2009).

Com relação à eficiência de óleos, Medice et al. (2007) relataram que o de C. citriodora reduziu em mais de $50 \%$ a severidade da ferrugem asiática da soja (Glycine max) e mostrou efeito direto sobre o patógeno. No presente trabalho, apesar deste óleo não apresentar efeito direto sobre Pcc A1, causou uma grande redução na severidade da podridão mole após $48 \mathrm{~h}$ da inoculação (Tabela 1).

Análise físico-química de folhas de alface tratadas com óleo essencial e extratos vegetais - $O$ teor de vitamina $\mathrm{C}$, a acidez titulável e o $\mathrm{pH}$ das plantas de alface tratadas com óleo de C. citriodora e extratos de $P$. aculeata (ramos com espinhos) e C. cytisoides (folhas) não diferiram da testemunha (Tabela 2). Estas mesmas variáveis foram influenciadas diferentemente pelos extratos de $S$. galheirensis (raiz), $P$. violacea e $P$. aculeata (folhas). O único extrato que afetou todas as variáveis físico-químicas analisadas foi o de C. desvauxii (folhas); observando-se redução do pH, elevação da porcentagem da ácidez titulável e do teor de vitamina C. Plantas de alface tratadas com o antibiótico agrícola Mycoshield $^{\mathbb{B}}$ diferiram da testemunha não tratada apenas quanto ao $\mathrm{pH}$, que foi elevado de 4,61 para 5,08.

Em termos de amplitude, o $\mathrm{pH}$ variou de 3,82 (C. desvauxii (folhas)) a 5,08 $\left(\right.$ Mycoshield $\left.^{\circledR}\right)$. A acidez variou de 0,032 (testemunha) a 0,065 ( $P$. aculeata (folhas)), enquanto que o teor de vitamina C variou de 19,04 ( $S$. galheirensis (raiz)) a 40,46 (C. desvauxii (folhas)).

É importante que plantas tratadas com extratos e óleos essenciais para manejo de doenças não tenham suas características físico-químicas alteradas. Caso isto ocorra, é necessário avaliar se o benefício obtido com o controle da doença compensa a perda percentual destas qualidades. Em geral, na cultura da alface, as características mais significantes são $\mathrm{pH}$, porcentagem de ácido cítrico, teor de vitamina $\mathrm{C}$ e de sólidos solúveis totais.

Os teores de sólidos solúveis totais para todos os tratamentos foi 0,0 ${ }^{\circ}$ Brix embora Freire et al. (2009) considerem $5,1^{\circ}$ Brix como o teor normal dessa cultivar. A explicação para este fato pode estar na idade das plantas (35 dias). Segundo Chitarra \& Chitarra (2005), os sólidos solúveis correspondem a todas as substâncias que se encontram dissolvidas em um determinado solvente, o qual, no caso das vegetais, é a água. São constituídos principalmente por açúcares, sendo variáveis com a espécie, a cultivar, o estádio de maturação e o clima. Desse modo, além da idade, os teores de $0,0^{\circ}$ Brix podem estar relacionados a algum ou alguns desses outros fatores. Menezes et al. (2005) encontraram teores de sólidos solúveis variando entre 0,18 e $0,33^{\circ}$ Brix em folhas de alface cv. Lisa minimamente processadas e armazenadas em atmosfera modificada. Já Marin et al. (2010), quando avaliaram o efeito do 1-metilciclopropeno na conservação de folhas de alface americana minimamente processadas, não observaram variação no teor de sólidos solúveis $\left(1,5^{\circ} \mathrm{Brix}\right)$ até o final do armazenamento. Nota-se que nestes dois casos, as plantas eram de cultivares diferentes, lisa e americana, e encontravam-se no estádio de maturação pós-colheita, diferentemente do presente trabalho onde a alface analisada foi do tipo crespa, as plantas tinham 35 dias e foram cultivadas em casa de vegetação.

Os teores de vitamina $\mathrm{C}$ nas folhas de alface tratadas com os extratos de C. desvauxii (folhas) e S. galheirensis (raiz) foram alterados para mais e para menos, respectivamente quando comparados às folhas não tratadas (Tabela 2). O aumento de vitamina C é uma característica aceitável e benéfica, visto que esta hortaliça é conhecida por armazenar altos teores desse componente nas folhas (Almeida, 2006). Freire et al. (2009) observaram que os teores de vitamina $\mathrm{C}$ em alface crespa cv. Veneranda variaram entre 35 e $40 \mathrm{mg} 100 \mathrm{~g}^{-1} \mathrm{em}$ diferentes níveis de salinidade. No presente trabalho, o extrato de $C$. desvauxii (folhas) proporcionou uma maior conservação da vitamina C (40,46 mg $\left.100 \mathrm{~g} \mathrm{~g}^{-1}\right)$ nas folhas de alface após tratamento. Ohse et al. (2001) também encontraram valores médios de $28,28 \mathrm{mg} 100 \mathrm{~g}^{-1}$ em seis cultivares de alface quando as mesmas foram cultivadas no sistema convencional e de $31,42{\mathrm{mg} 100 \mathrm{~g}^{-1} \mathrm{em}}^{-}$ sistema hidropônico.

Os extratos de C. desvauxii (folhas) e de $P$. aculeata (folhas) aumentaram a acidez titulável (Tabela 2) e acarretaram uma redução no $\mathrm{pH}$ das folhas tratadas. Segundo Chitarra \& Chitarra (2005), no 
suco de tecidos vegetais, quando a faixa de concentração de ácidos orgânicos varia entre 0,5 e $2,5 \%$, o $\mathrm{pH}$ diminui com o aumento da acidez sendo utilizado como indicativo dessa variação. A elevação do $\mathrm{pH}$ nas folhas tratadas com o antibiótico agrícola Mycoshield ${ }^{\circledR}$ também pode ser explicada por estes mesmos princípios pois observouse aumento no $\mathrm{pH}$ e diminuição na acidez. Resultados semelhantes foram encontrados por Alcântara (2009) quando utilizou o sanitizante ácido peracético a $100 \mu \mathrm{L} \mathrm{L}^{-1}$ em folhas de alface cv. Verônica observando um aumento no pH de 6,03 para 6,36 e uma redução na acidez de $0,14 \%$. Do mesmo modo, quando Freire et al. (2009) avaliaram diferentes níveis de salinidade no cultivo da alface 'Veneranda', observaram que o aumento do $\mathrm{pH}$ foi dose dependente chegando a 6,1. Este valor de $\mathrm{pH}$ confirmou a diminuição na acidez que também foi dose dependente e chegou a $0,07 \%$. Apesar dos valores de $\mathrm{pH}$ observados neste trabalho diferirem dos encontrados por outros autores, um conjunto de fatores já mencionados podem ter afetado esta variável.

Em conclusão, os resultados sugerem que o óleo de $C$. citriodora e os extratos de ramos com espinhos de $P$. aculeata e folhas de $C$. cytisoides podem ser utilizados para controle da podridão mole da alface em sistema de cultivo protegido, sem comprometimento dos teores de ácido ascórbico (vitamina $\mathrm{C}$ ), acidez e do $\mathrm{pH}$ das plantas. No entanto, para serem empregados em sistemas convencionais, devem ser ainda testados em campo.

\section{REFERÊNCIAS}

ALCÂNTARA EM. 2009. Caracterização física, química e microbiológica de morango, alface e cenoura orgânicos. Lavras: UFLA 107 p (Tese de doutorado)

ALMEIDA D. 2006. Manual de culturas horticolas. Editorial Presença. $346 \mathrm{p}$.

ALVARADO ICM; MICHEREFF SJ; MARIANO RLR; SILVEIRA EB; QUEZADO-DUVAL AM; REZENDE LV; CARDOSO E; MIZUBUTI, ESG. 2011. Characterization and variability of soft-rot causing bacteria in Chinese cabbage in Northeastem Brazil. Journal of Plant Pathology 93: 173-181.

BEZERRANETOE; ANDRADEAG; BARRETO
LP. 2004. Análise química de tecidos e produtos vegetais. Recife: UFRPE 80p.

BURT S. 2004. Essential oils: their antibacterial properties and potential applications in foods - a review. International Journal of Food Microbiology 94: 233-253.

CHITARRA MIF; CHITARRA AB. 2005. Póscolheita de frutas e hortaliças: fisiologia e manuseio. Lavras: UFLA, 785 p.

COSTA CMGR; SANTOS MS; BARROS HMM; AGRA PFM; FARIAS MAA. 2008. Óleo essencial de citronela no controle da bactéria fitopatogênica Erwinia carotovora. Tecnologia e Ciência Agropecuária 2: 11-14.

COSTA CMGR; SANTOS MS; BARROS HMM; AGRA PFM; FARIAS MAA. 2009. Efeito inibitório do óleo essencial de manjericão sobre o crescimento in vitro de Erwinia carotovora. Tecnologia e Ciência Agropecuária 3: 35-38.

CUNICO MM; MIGUEL OG; MIGUEL MD; CARVALHO JLS; PEITZ C; AUER CG; GRIGOLETTI JUNIOR A. 2003. Estudo da atividade antinfúngica de Ottonia martiana Miq. Piperaceae: um teste in vivo. Visão acadêmica 4: 77-82.

DE BOER SH; KELMAN A. 2001. Erwinia Soft Rot Group In: SCHAAD NW; JONES JB; CHUN W. (eds). Laboratory guide for identification of plant pathogenic bacteria. Minnesota: The American Phytopathological Society. 372p.

FREIRE AG; OLIVEIRA FA; CARRILHO M JSO; OLIVEIRA MKT; FREITAS DC. 2009. Qualidade de cultivares de alface produzida em condições salinas. Caatinga 22: 81-88.

JEONG MR; PARK PB; KIM DH; JANG YS; JEONG HS; CHOI SH. 2009. Essential oil prepared from Cymbopogon citrates exerted an antimicrobial activity against plant pathogenic and medical microorganisms. Mycobiology 37: 48-52.

KOWALSKA B; SMOLINSKA U. 2008. The effect selected plant materials and extracts on the development of bacterial diseases on onion. Vegetable Crops Research Bulletin 68: 33-45.

LEITE SP; VIEIRA JRC; MEDEIROS PL; LEITE RMP; LIMA VLM; XAVIER HS; LIMA EO. 2006. Antimicrobial activity of Indigofera suffruticosa. The Journal and Oxford University Press 3: 261-265.

LEKSOMBOON C; THAVEECHAI N; KOSITRATANA W. 2001. Potential of plant extracts for controlling citrus canker of lime. Kasetsart Journal: Natural Science. 35: 392-396.

LIMA JS; PEREZ JO; BARROS PN; AZEVEDO LC; MENDES RB; PESSOA RA. 2010. Ação fungitóxica de extratos vegetais de plantas da caatinga sobre o crescimento micelial de Lasiodiplodia theobromae (Pat.) Griffon \& Maubl.em Vitis vinifera $\mathrm{L}$. In: CONGRESSO NORTE-NORDESTE DE PESQUISA E INOVAÇÃO, 5. Anais... Maceió: CONNEPI. p. 23-26.

MARIANO RLR; SILVEIRA EB. 2005. Manual de práticas em fitobacteriologia. $2^{\mathrm{a}}$ Ed. Recife: UFRPE. 184p.

MARIN T; MONTANUCCI JR; BENASSI MT; YAMASHITA F. 2010. Embalagem ativa para alface americana (Lactuca sativa $\mathrm{L}$.) minimamente processada. Semina: Ciências Agrárias 31: 653-660.
MEDICE R; ALVES E; ASSIS RT; MAGNO JÚNIOR RG; LOPES EAGL. 2007. Óleos essenciais no controle da ferrugem asiática da soja Phakopsora pachyrhizi Syd. \& P. Syd. Ciência e Agrotecnologia 31: 83-90

MENEZES EMS; FERNANDES EC; SABAASRUR AUO. 2005. Folhas de alface lisa (Lactuca sativa) minimante processadas armazenadas em atmosfera modificada: análises físicas, químicas e físico-químicas. Ciência e Tecnologia de Alimentos 25: 60-62.

MICHELIN DC; SANNOMIYA M; FIGUEIREDO ME; RINALDO D; SANTOS, LC, SOUZA-BRITO ARM; VILEGAS W; SALGADO HRN. 2008. Antimicrobial activity of Byrsonima species (Malpighiaceae). Revista Brasileira de Farmacognosia 18: 690-695.

OHSE S; NOGUEIRA FILHO H; MANFRON PA; DOURADO-NETO D. 2001. Composição centesimal e teores de vitamina $\mathrm{C}$, cálcio e fósforo de seis cultivares de alface produzidas sob dois sistemas de cultivo. Insula 30: 47-62.

OLIVEIRA AMC; PINTO GAS; BRUNO LM; AZEVEDO EHF. 2005. Avaliação da qualidade higiênica de alface minimamente processada, comercializada em Fortaleza, CE. Higiene Alimentar 19: 80-85.

REN J; PETZOLDT R; DICKSON MH. 2001. Genetics and population improvement resistance to bacterial soft rot Chinese cabbage. Euphytica 117: 197-207.

SHANER G; FINNEY RE. 1977. The effect of nitrogen fertilization on the expression of slow-mildewing resistance in Knox wheat. Phytopathology 67: 1051-1056.

SILVA AMF; MARIANO RLR; MICHEREFF SJ; SILVEIRA EB; MEDEIROS FHV. 2007. Levantamento da intensidade da podridão-mole em alface e couve-chinesa em Pernambuco. Caatinga 20: 84-93.

SILVA MB; MORANDI MAB; JUNIOR TJP; VENZON M; FONSECA MCM. 2010. Extratos de plantas e seus derivados no controle de doenças e pragas In: VENZON M; JÚNIOR TJP PALLINI (coord.). Controle alternativo de pragas e doenças na agricultura orgânica. Viçosa: EPAMIG. p. 33-54.

VIGO SC; MARINGONI AC; CAMARA RC; LIMA GPP. 2009. Ação de tinturas e óleos essenciais de plantas medicinais sobre o crestamento bacteriano comum do feijoeiro e na produção de proteínas de indução de resistência. Summa Phytopathologica 35: 293-304.

VIGO-SCHULTZ SC; STANGARLIN JR; FRANZENER G; PORTZ RL; KUHN OJ; SCHWAN-ESTRADA KRF. 2006. Avaliação da eficácia da tintura etanólica de guaco (Mikania glomerata) no controle da podridão negra (Xanthomonas campestris pv. campestris) em couve-flor. Semina: Ciências Agrárias 27: 515-524.

YAGUIU P. 2008. Qualidade de hortaliças e sustentabilidade de sistemas orgânicos em Sergipe. São Cristovão: Universidade Federal de Sergipe. 99p (Dissertação mestrado).

ZENEBON O; PASCUET NS; TIGLEA P. 2008. Métodos físico-químicos para análises de alimentos. São Paulo: Instituto Adolfo Lutz. $1020 \mathrm{p}$. 